\title{
O filho do chefe: Estado Colonial e produção da hereditariedade política na Nova Caledônia ${ }^{1}$
}

\author{
Éric Soriano
}

\begin{abstract}
Resumo: As lógicas da transmissão do poder hereditário no mundo canaco são analisadas aqui a partir de uma pesquisa sobre a representação excessiva de "líderes" na política na Nova Caledônia colonial na década de 1950. Este estudo baseia-se na prosopografia de melanésios eleitos após o fim do Código do Indigenato (1946), na pesquisa nos arquivos da Administração Colonial e em entrevistas com representantes eleitos e ex-funcionários eleitos do período. Parece que esta representação excessiva de líderes é mais o produto de uma instrumentalização simbólica operada por eles do que uma legitimidade "tradicional" de hereditariedade que seria convertida em política. No contexto canaco, o que conta para esses "líderes" se imporem na política é a capacidade de controlar um espaço consagrado pela administração e sua localização na fronteira com o Estado Colonial.
\end{abstract}

\section{Plano do artigo}

1. A glória política dos líderes?

Trajetórias nas fronteiras do Estado Colonial

Líderes na política ou poder do parentesco

\section{Paternidade não conversível}

Uma desintegração paradoxal

Duas configurações de herança política

\section{Sobre o autor}

\section{Éric Soriano}

Professor de Ciência Política na Universidade Paul Valéry (Montpellier III) e pesquisador da UMR 5281 ART-Dev (atores, recursos e territórios em desenvolvimento). O seu trabalho centra-se na Sociologia Histórica dos governos coloniais e nas relações raciais. Ele publicou (com Delphine Naudier), "Colette Guillaumin": a raça, o sexo e as virtudes da analogia, In: Cahiers du Genre (48, 2010, p. 193-214) e 0 fim dos "Indígenas"da Nova Caledônia: o colonial à prova da política (1946-1976). Paris: Karthala, 2014.

eric.soriano@univ-montp3.fr

\footnotetext{
1 Tradução livre de Ana Vanali. Texto original "Le fils du chef : État colonial et production de l'hérédité politique en NouvelleCalédonie», Critique internationale, vol. 73, № 4, 2016, p. 37-52. Disponível em https://www.cairn.info/revue-critiqueinternationale-2016-4-page-37.htm. Acesso 25.outubro.2017. Autorização para a publicação da tradução cedido por Catherine Burucoa, responsável da Revista Critique Internationale (Sciences Po, Centre de Recherches Internationales) no dia 15 de novembro de 2017.
} 


\title{
O filho do chefe: Estado Colonial e produção da hereditariedade política na Nova Caledônia
}

\author{
Éric Soriano
}

A generalização progressiva da prática eleitoral nos estados insulares da Oceania definitivamente perturbou a lógica "tradicional" de transmissão e exercício da autoridade². A organização das eleições nacionais colocou em questão o futuro dos líderes, dos anciãos e dos homens grandes ${ }^{3}$. Qual papel de poder desempenhavam esses personagens centrais cuja legitimidade se baseava no uso graduado dos status herdados dentro de múltiplas unidades políticas (reinados, cacicados, tribos ...) agora reunidos pelos novos Estados? Nessa região, o legado de filiação direta dos cargos de poder era uma prática generalizada, mesmo que a oposição relativa entre a liderança hereditária dos chefes polinésios e as formas mais empresariais de acesso à autoridade na Melanésia testemunhassem uma série de situações ${ }^{4}$. $O$ interesse pelo contexto novo caledônio não é somente ele ter tido o primeiro quadro de experimentação do sufrágio universal, mas também por ter incluído as populações com diferentes modos de organização: desde as formas centralizadas de poder das Ilhas Lealdade, onde a liderança local opera um controle forte sobre estratégias matrimoniais, até os modos de exercício mais difusos de autoridade da ilha principal da Grande Terre $^{5}$, onde o poder do chefe é às vezes reduzido a um mero papel de representação ${ }^{6}$. Esta variedade teve sua contrapartida em estratégias de colonização diferenciadas. Na Grande Terre, a metrópole procedeu a

${ }^{2}$ WHITE, Geoffrey M. e LINDSTROM, Lamont (orgs). Chefes de hoje: liderança tradicional do Pacífico e o Estado pós-colonial. Standford: Stanford University Press, 1997.

${ }^{3}$ LAWSON, Stephanie. Tradição x Democracia no Pacífico Sul: Fiji, Tonga e Samoa Ocidental. Cambridge: Cambridge University Press, 1996.

${ }^{4}$ SAHLINS, Marshall. "Homem pobre, homem rico, homem grande, chefe: tipos políticos na Melanésia e Polinésia". In: Estudos Comparados em Sociedade e História, 5 (3), 1963, p. 285-303.

DOUGLAS, Bronwen. "Ranque, poder, autoridade: uma reavaliação da liderança tradicional nas sociedades do Pacífico Sul". In: The Journal of Pacific History, 14 (1), 1979, p. 2-27.

ALLEN, Michael. "Anciãos, chefes e homens grandes: legitimidade da autoridade e evolução política na Melanésia". In: Ethnologist American, 11 (1), 1984, p. 20-41.

THOMAS, Nicholas. "A força da Etnologia: origens e importância da divisão Melanésia/Polinésia". In: Current Anthropology, 30 (1), 1989, p. 27-41.

${ }^{5}$ Nota da tradutora: Grande Terre é a maior e principal ilha da Nova Caledónia, território francês na Oceania. O explorador britânico James Cook avistou Grande Terre em 1774 e chamou-lhe "Nova Caledónia", sendo Caledónia um nome latino para algumas partes do norte da atual Escócia. Depois, o nome de "Nova Caledónia" foi usado para designar Grande Terre e as ilhas circundantes. A maior localidade em Grande Terre é Nouméa, a capital da Nova Caledónia.

${ }^{6}$ BENSA, Alban. Os caminhos da aliança. Paris: Selaf, 1982. 
importantes deslocamentos e acantonamentos das populações em reservas para instalar um assentamento europeu. Por outro lado, nas Ilhas Lealdade foram constituídas reservas integradas que não colocaram em questão a organização das lideranças locais.

A partir de 1946, os governos metropolitanos imaginaram que uma transição democrática dissiparia os efeitos de uma colonização brutal que oficialmente estaria finalizada com a abolição do Código do Indigenato7. Em 1951, os "indígenas" pegaram os caminhos das urnas para as eleições legislativas e, dois anos mais tarde, nove deles investiram nas posições eletivas para o Conselho Geral. Sua presença renova um espaço de representação até agora constituído em torno das elites coloniais. A Sociologia dos primeiros melanésios eleitos confirma a existência de uma característica singular: durante três mandatos, de 1953 a 1967, a metade dentre eles garantiu uma posição de grande ou de pequeno administrador em um "distrito" ou em uma "tribo" no interior das reservas. Suas posições se estabilizaram em seguida, e até hoje estão presentes, com cerca de um terço dos representantes eleitos. É ainda mais surpreendente que apenas 350 pessoas, de uma população de cerca de 40000 melanésios, assumam esse papel adjetivado de "tradicional" ou "habitual".

$\mathrm{Na}$ época do Indigenato, a identificação desses atores respondia à necessidade de encontrar substitutos em cada distrito, com a administração colonial apostando na possível concentração de poder nas mãos de um líder. Isso deveria assegurar a cobrança do imposto de capitação, a execução adequada das corveias, a realização das operações de aplicação da ordem e a escolaridade das crianças nas escolas "indígenas"8. As configurações políticas locais testemunharam, no entanto, uma grande variabilidade dos papéis, dos títulos e das classificações, que refletiam a complexidade das tarefas e dos cargos de autoridade (líderes, mestres da terra, guerreiros, anciãos ...). Como vários antropólogos demonstraram, a repressão colonial e a intervenção administrativa foram o suporte para uma redefinição dos chefes locais ${ }^{9} \mathrm{e}$

\footnotetext{
${ }^{7}$ Nota da tradutora: O Código do Indigenato foi imposto pelo governo francês a todas as suas colônias em 1887. Em geral, o Código submeteu os povos nativos e os trabalhadores migrantes ao trabalho forçado, à condução noturna, às requisições, aos impostos sobre a captação nas reservas e a uma série de outras medidas igualmente degradantes. Era um compêndio de medidas discricionárias destinadas a defender a "boa ordem colonial", que se baseava na institucionalização da desigualdade e da justiça. Este código foi constantemente "melhorado" para adaptar os interesses dos colonos às "realidades do país". Ele distinguiu a população entre duas categorias de cidadãos: os franceses (de origem metropolitana) e nativos, ou seja, africanos negros, malgaxes, argelinos, índios ocidentais, melanésios, etc., bem como trabalhadores imigrantes. Os cidadãos nativos foram privados da maior parte da liberdade e dos seus direitos políticos; eles conservaram no plano civil apenas seu status pessoal, de origem religiosa ou tradicional. O Código foi acompanhado por todos os tipos de proibições, cujos delitos eram puníveis com prisão ou deportação. Este sistema de desigualdade social e jurídica durou até 1946, vários anos após os Acordos de Genebra (23 de abril de 1938) proibir todas as formas de trabalho forçado. Após a lei de 7 de abril de 1946, que aboliu o Código do Indigenato, os nativos (Nova Caledônia, Madagascar, Argélia, etc.) puderam circular livremente durante o dia e noite, e recuperaram o direito de residir onde queriam, além de poderem trabalhar livremente. Códigos semelhantes foram adotados pelos britânicos, pelos portugueses, pelos holandeses, etc. Não foram apenas os franceses que adotaram esse tipo de regime.
}

${ }^{8}$ MERLE, Isabelle. "Da "legalização" da violência em um contexto colonial. 0 regime do indigenato em questão". In: Politix, 17 (66), 2004, p. 137-162.

${ }^{9}$ NAEPELS, Michel. "O futuro colonial de uma liderança canaca (Houailou, Nova Caledônia)". In: Annales. História, Ciências Sociais, Grade 65, 4, 2010, p. 913-943. 
uma reformulação dos territórios do poder, mas, apesar do confinamento nas reservas, a preservação das cerimônias de intercâmbio entre clãs no momento dos casamentos e dos falecimentos, a manutenção dos locais sagrados e a transmissão dos mitos continuaram a alimentar um "discurso de ordem baseado no princípio de consenso e dos status herdados ${ }^{\prime 10}$. Portanto, a partir do momento em que as regras mais restritivas do Indigenato foram abolidas, a excessiva representação dos chefes na política criou uma crença na perenidade de um poder "costumeiro" mais frequentemente adquirido pela hereditariedade, convertível em política.

Nosso estudo é baseado na prosopografia de todos os representantes eleitos "indígenas" pósindigenato até 1977 , bem como na pesquisa dos arquivos da Administração Colonial e nos relatórios da Força Militar sobre a organização das eleições nas reservas. Este trabalho foi completado por uma quarentena de entrevistas com dirigentes políticos sobre suas trajetórias de engajamento e sobre o contexto da mobilização eleitoral no momento da sua entrada na política. Ele mostra que essa valorização das posições "tradicionais" se deve às estratégias de conjunções da administração com as elites coloniais para fazer valer o princípio do nascimento. No entanto, o uso político da hereditariedade depende principalmente da capacidade de controlar um espaço consagrado pela administração colonial. Aqueles que, entre os representantes eleitos, desfrutam de uma posição de liderança mostraram uma aptidão muito maior para legar sua posição "costumeira" aos seus descendentes diretos do que transmitir sua função política. A herança política, portanto, depende do controle de recursos sociais e partidários. Só funciona ao preço de um trabalho político, como se a "tradição" herdada só pudesse ser resultado de uma dinâmica empreendedora.

\section{A glória política dos líderes?}

No momento quando os nove primeiros melanésios eleitos compuseram o Conselho Geral em 1953, as práticas de transmissão hereditária dos cargos eletivos não puderam existir uma vez que "a" política estava sendo formada. A cidade escolheu manter um sistema de lista, o que orientou muito o modo de implantação dos representantes eleitos e o funcionamento das organizações envolvidas. Candidatos "indígenas" são recrutados através de duas grandes associações missionários formadas em 1947 para conter as tentativas de implantação do Partido Comunista Caledoniana (PCC): a União dos Indígenas Caledonianos Amigos da Liberdade e da Ordem (UICALO) e a Associação dos Indígenas Caledonianos e dos

DEMMER, Christine. "Segredos e organização política em Canaca: para sair das categorias privada/pública". In: L'Homme, 190 (2), 2009, p. 79-104.

10 BENSA, A. "Pai de Pwädé: de volta à uma etnologia de longo prazo". In: BENSA, A. et al. A pesquisa. Paris : La Découverte, 2008, p. 23. 
Lealistas Franceses (AICLF). Ambos participaram ativamente da criação do principal partido político da ilha, a União Caledoniana (UC), em 1951. Durante quase vinte anos, exerceram uma forte influência na constituição das listas de candidaturas. A sua vasta rede de escolas "indígenas" coloca-os em uma posição de força em comparação com as elites da Nova Caledônia ausentes das reservas. As marcas de distinção das quais os candidatos recrutados são portadores desenham uma relação privilegiada com o mundo colonial, mas muitas vezes se expressam na linguagem do parentesco.

\section{As trajetórias nas fronteiras do Estado colonial}

Os eleitos "indígenas" dos primeiros mandatos nasceram no início do século XX em espaços marcados por várias décadas de colonialismo. É nesta ação conjunta do Estado com as missões católicas e protestantes, como nas relações mantidas com o colonato europeu que se teceu a ambivalência das relações coloniais. Na verdade, para o mundo "indígena", as instâncias coloniais começam a se tornar fontes de poder, e seria inútil falar da administração sem os indígenas e dos indígenas sem os colonos ${ }^{11}$. No entanto, a precariedade da urbanização e da escolarização das populações colonizadas contribui para manter a preeminência do parentesco nas relações privilegiadas dentro das reservas. A estabilidade do poder, nessas reservas, foi construída sempre pela capacidade de orientar as alianças matrimoniais entre grupos e garantir a sua durabilidade através do trabalho de trocas recíprocas. Nesses espaços de reserva, há muito afastados da sociedade caledoniana em formação, os primeiros representantes eleitos se situavam na vanguarda da fronteira colonial. A sua integração no mundo missionário é mensurável com a longevidade de sua passagem pelas escolas protestantes e católicas. Dos primeiros 47 eleitos (1946-1977), 20 obtiveram o certificado de estudo em diferentes idades (entre 14 e 23 anos), enquanto a maioria dos outros simplesmente não se submeteram ao exame. No entanto, podemos citar vários casos de líderes que não tendo obtido o diploma, se distinguiam por um investimento sustentável (como administradores, catequistas ...) no seio das escolas católicas e protestantes. Austin Dalap Touyada, por exemplo, eleito pela UC em 1962, reprovou várias vezes nos exames de certificação dos estudos, mas seu forte envolvimento no seminário de Saint Leo, na comunidade de Païta, permitiu-Ihe obter um amplo reconhecimento no meio da educação católica.

Assim, mesmo que não constituam um grupo social em si, os candidatos selecionados têm pelo menos em comum a experiência de relações externas com seu grupo de parentesco de origem. Seu percurso singular e ascendente encontra seu ponto de partida na proximidade com o mundo colonial. Se

\footnotetext{
11 TREPIED, Benoit. Uma prefeitura da França Colonial: Koné-Nova Caledônia. Paris: Karthala, 2010.

FAUGERE, Elsa. "A fábrica de identidade nas Ilhas Lealdade. Como se pode ser colono canaco?" In: Ethnologie française, 32 (4), 2002, p. 629-635.
} 
avaliarmos suas origens sociais pelo nível de inserção de seus pais nas instâncias missionárias e/ou nas atividades assalariadas deste último (as mães estão quase ausentes nesse tipo de localização), observamos que esses candidatos se destacam do resto da população melanésia. A situação de seus pais no momento da sua entrada na política ilustra as primeiras lógicas da seleção: a maioria faz parte desses pequenos intermediários que emergiram localmente. Nenhum representante eleito pôde se prevalecer de um pai diplomado visto o acesso dos "indígenas" à certificação escolar ser proibida pelo Código do Indigenato. Até as eleições de 1967, não encontramos filhos de funcionários regulares do setor privado, cujos pais estavam, neste setor, em uma situação de precariedade salarial, devida, em particular, à prática dos trabalhos por tarefa, exigindo pouca qualificação. Em contraste, um pouco mais de um quarto dos eleitos tinham os pais empregados no setor público, frequentemente como "patrões" da administração ou como funcionários da prefeitura recrutados pelas comissões municipais criadas no final da década de 1950 ou nos dispensários localmente estabelecidos. Na maioria dos casos, esses empregos são contratuais e as nomeações são resultados de práticas de cooptação amplamente utilizadas nas prefeituras exclusivamente controladas pelos europeus. Desprovidos de diplomas, os pais desses eleitos estão entre os primeiros "indígenas" a experimentar um benefício salarial e, embora seja difícil avaliar sua regularidade, esses cargos permitem o acesso familiar a recursos relacionados ao mundo europeu.

As distinções sociais mais valorizadas, no entanto, são de posições adquiridas pelos pais nas instituições religiosas. Entre 1953 e 1977, mais de um eleito em cada seis pôde reivindicar tal herança. A partir do período entre as duas guerras, certos grupos de parentesco começaram a se constituir de grupos de pastores ou de catequistas. Esta filiação profissional garantiu uma visibilidade construída sobre um sucesso escolar estendido por uma atividade de ensino e/ou de animador da vida paroquial. Ser catequista, pastor ou monitor da educação religiosa confere um prestígio particular e atesta sobretudo um conhecimento institucional de capacidade de mediar com o Estado ${ }^{12}$. Há, portanto, vários casos de famílias melanésias consideradas como "famílias de instrutores" (os Naouna em Pouembout ou os Pouyé em Ponéhihouen) por terem a reputação local de poder contar com vários diplomados no ensino primário dentro de uma mesma irmandade.

A categoria mais enigmática é a dos pais que aparentemente não possuem nenhuma atividade remunerada. Os guardas florestais os identificam como "produtores" em suas notas informativas sobre os representantes eleitos. Há aqueles que parecem ter uma atividade agrícola propriamente dita e aqueles que estão satisfeitos de viver com a sua produção, mas nada diz que os primeiros se beneficiam de um status superior aos segundos. A baixa renda retirada da exploração da terra não pode confirmar esta

\footnotetext{
12 SALAUN, Marie. "Os instrutores canacos ou as elites nativas impossíveis na Nova Caledônia". In: Genesis, 43, 2001, p. 71-88.
} 
distinção ${ }^{13}$ e torna esta categoria inoperante. Alguns "produtores" provêm de famílias que se beneficiam de acesso privilegiado à terra, portanto, uma posição importante na reserva ${ }^{14}$, mas o número daqueles que vivem apenas de sua própria produção se reduz amplamente depois do Indigenato. Essa tendência é o resultado da progressão das políticas de promoção das empresas agrícolas estatais a partir da década de 1930. Somente após o Indigenato é que algumas famílias puderam se prevalecer de rendas agrícolas regulares que muitas vezes apenas confirmam sua ascendência em relação aos "clãs" desprovidos de terra. Na verdade, o uso da categoria "produtores" revela a que ponto os guardas e os administradores coloniais estavam longe de buscar a extensão das gradações dos status entre os indivíduos.

\section{Os líderes da política ou o poder do parentesco}

É ao entrar nos detalhes das biografias desta geração de representantes eleitos que captamos a complexidade de sua inscrição no parentesco e os limites de uma abordagem exclusivamente prosopográfica neste tipo de pesquisa: compreender o status local desses eleitos, muitas vezes é descobrir o jogo sutil de uma grande variedade de níveis hierárquicos fragmentados em diversas composições similares. As entrevistas também são uma oportunidade para apreciar a forma como os atores traduzem seu status local. Com uma exceção, os eleitos da primeira geração (1953-1977) nasceram "na tribo" e descobriram Nouméa apenas no contexto de sua atividade escolar, profissional ou política. Se excluirmos os poucos líderes originários das tribos próximas de Nouméa, poucos são os que conseguiram conhecer o modo de vida urbana antes da idade adulta. Quase todos eles passaram a infância restritos a um pequeno grupo familiar e sempre apresentam sua "tribo" como o fermento de uma história coletiva. A maneira como eles começam sua história de vida traduz um desejo de mostrar uma ligação particular a um espaço de origem no interior da comuna e de se colocar no quadro de uma genealogia precisa, para detalhar os lineamentos familiares em que se integram: "Eu sou de Coula, da tribo de Boreare, do clã do chefe. Temos ligações com o outro lado, com as ilhas e com outros clãs da comuna. Mas o que é importante para compreender onde eu vivi quando eu era pequeno, é a família, é o costume que vai dizer isso. Porque a comuna não significa nada a menos que nos situe em relação à política e à administração. Lá, dentro da tradição, as ligações, elas vão além da comuna, são caminhos que vão a outro lugar e a partir daí entendemos quem somos" 15 .

\footnotetext{
13 DOUMENGE, Jean-Pierre. "Da roça ... para a cidade. Melanésios e seus espaços na Nova Caledônia". In: Área Universitária de Bordeaux-Talence, CEGET / CNRS, Obras e documentos de Geografia Tropical, 488, 1982, p. 376.

${ }^{14}$ BENSA, A. "Terra canaca: problema político de ontem e de hoje". In: Estudos Rurais, 127-128, julho-dezembro 1992, p. $107-131$.

${ }^{15}$ Entrevista com Delin Wema, Noumea, 8 de outubro de 1996.
} 
Os termos são ainda mais vagos, pois sempre existe essa insistência em relatar a multiplicidade dos laços de parentesco que os unem à uma história local e que vão muito além das atribuições administrativas. Portanto, as referências coletivas usadas são frequentemente sujeitas a cautela. Elia Thidjine, por exemplo, eleito entre 1953 e 1957, vem do norte de Hoot ma Whaap, do extremo norte da Grande Terre. Os Tidjin têm uma posição importante em Teâ Nelemwâ (nome denotando a filiação), mas é difícil de definir o relacionamento entre esse nome dado pela administração e sua posição no "clã" Tidjin ${ }^{16}$.

A expressão do apego a um grupo de parentesco é então uma oportunidade para distinguir entre duas formas de status social, a tradicional e a modernas "Na tradição, sou algo específico. Tenho um papel que os antigos me atribuíram em função do meu pertencimento ao clã. É verdade que as coisas podem mudar durante a vida. À medida que envelhecemos, subimos na hierarquia como vocês dizem [risos] ${ }^{17}$, temos mais responsabilidades, mas é importante separar os dois senão as pessoas vão sempre lhe culpar. É por isso que os velhos sempre tomam o controle daquilo que não tem alguém encabeçando ou porque você foi eleito ou porque foi para a escola. Na tradição, cada um tem seu papel e alguém importante na vida pode não ser nada dentro da tradição e vice-versa"18.

A avaliação do próprio status local pode realmente resultar em infinitas digressões, mas ela diz muita da realidade de um espaço social onde a posição de cada um provavelmente será objeto de declarações difíceis de verificar. Este exercício ao menos nos permite dizer que o acesso a um status em uma filiação de origem só existe sob a condição de um trabalho sobre as relações locais. Se as fórmulas de depreciação dos adversários políticos servem para distinguir entre "aqueles que são alguma coisa na tradição" e os outros, alguns eleitos entrevistados admitem a natureza plural das possíveis posições, em particular na Grande Terre. Quando eles não foram nomeados como chefes pela administração, eles se dizem os "porta-vozes do clã" ou "do clã da liderança" sem que possamos saber a importância efetiva de sua posição, muitas vezes sujeita localmente a várias apreciações. No entanto, a maioria dos eleitos entrevistados sobre a Grande Terre relatam a flexibilidade relativa de seus espaços de reconhecimento e pode acontecer que um grande chefe não seja ele mesmo filho de outro grande chefe, como é o caso de Gabriel Païta, um dos representantes eleitos da época. Maurice Nenou, eleito territorial da comuna de Houaïlou, explica assim: "Somente os europeus acreditam que não somos capazes de nos adaptarmos. Alguém digno é alguém que pode adquirir um lugar na tradição. Se ele respeitar as regras do costume, se ele passar por aqueles por quem ele deve passar, nada está fechado. Claro que é melhor não estar sozinho.

\footnotetext{
${ }^{16}$ MONNERIE, Denis. "Resistência ao colonialismo, cultura, costume e política (região de Arama e Hoot ma Whaap). In: Journal de la sociéte des océanistes, 117 (2), 2003, p. 213-231.

${ }^{17}$ Nota da tradutora: É utilizada a expressão "prende du galon". A origem dessa expressão é militar e data de meados do século XIX. Significa que quanto mais o uniforme tem listras, mais responsabilidades se tem, portanto, ocupa uma posição importante.

${ }^{18}$ Entrevista com Paul Napoarea, Koné, 23 de julho de 1994.
} 
É melhor que todo o clã seja merecedor. Mas quando alguém está estudando, o Conselho dos Anciãos tem interesse em envolvê-lo porque ele fortalece o costume por sua presença e, como resultado, o costume o fortalece" ${ }^{19}$.

Em muitos casos, constatamos que posições e recursos são adquiridos graças a uma melhor inserção escolar ou profissional que contribuem para a aquisição de uma posição superior em sua "tribo" de origem. Observamos também que as modalidades de inserção de um eleito em seu clã de origem dependem da evolução histórica da reserva de acesso à terra. Sejam elas quais forem, as origens concretas da evolução de um status local deve ser traduzida em termos de parentesco.

Portanto, o que tendemos a considerar, erroneamente, são como pequenas diferenças estão ancoradas em um espaço cujo conhecimento é acessível apenas ao custo de um trabalho sobre a mitologia dos locais de origem dessas diferenças. Abordar estas questões com um representante eleito é, portanto, retornar ao histórico de uma localidade, incluindo o lugar de seu "clã" e sua cadeia de parentesco estendida. Como Michel Naepels ressalta, "a posição de um indivíduo ou de uma família em uma tribo também depende (...) de suas capacidades de se chegar a um consenso sobre a origem histórica desta posição"20. O "romance tradicional" é, portanto, uma questão de reconstrução, muitas vezes mobilizado como um discurso sobre si mesmo. O discurso de herança não corresponde necessariamente ao da posição adquirida. É sobretudo um repertório obrigatório cuja vocação é registrar-se em um grupo e registrar esse mesmo grupo em uma história que será mais legítima quanto mais longa for. Este trabalho de e sobre o parentesco refere-se à manutenção contínua de relações específicas: trata-se de fazer viver as alianças, de respeitar os rituais, de estar presente, de falar publicamente. Ele consiste igualmente de evidenciar as estratégias matrimoniais, mas também de operar um controle permanente sobre a mitologia dos lugares. As poucas vezes que podemos comparar as versões entregues por nossos interlocutores com o trabalho dos etnólogos, observamos diferenças significativas entre as versões históricas propostas por uns e por outros ${ }^{21}$. Além disso, o lugar de cada um é ainda mais difícil de avaliar quando nos encontramos em um contexto fracamente institucionalizado: existem lugares onde se podem identificar os status específicos e outros onde as distinções parecem mais desfocadas. Este lugar é mais fácil de indicar nas "grandes famílias" e em contextos onde a hereditariedade parece se constituir em um recurso essencial. Assim, o apego a uma

\footnotetext{
${ }^{19}$ Entrevista com Maurice Nenou, eleito para o Ajuntamento para a Caledônia na República (RPCR), Noumea, 13 de julho de 1994.

20 NAEPELS, Michel. Histórias das terras de canaco. Conflitos agrários e relações sociais na região de Houailou. Paris: Belin, 1998, p. 138-139.

${ }^{21}$ A título de exemplo, citamos a comparação entre a versão apresentada pelo próprio Gabriel Païta da história de sua "tribo", em PAITA, Gabriel; CAZAUMAYOU, Jerome e DECKKER, Thomas de. Gabriel Païta, testemunho de um canaco. D'Opao no país da Nova Caledônia. Paris: L'Harmattan, 1999, p. 21-26, e a versão da história dessa mesma tribo de Jean Guiart, Estrutura da liderança na Melanésia do Sul. Paris: Instituto de Etnologia, Museu do Homem, 2a edição, 1992.
} 
"tribo" ou a uma linhagem patrilinear induz uma diversidade de trajetórias individuais ao mesmo tempo que são o fermento de experiências comuns.

A integração a uma ecologia, a uma linguagem, a um parentesco, a participação em conflitos agrários funciona como características particulares que distinguem os indivíduos, mas produzem uma unidade relativa. No entanto, se é fácil reconstituir as relações de parentesco entre os eleitos, nossos dados sobre o conjunto do período também mostram uma situação paradoxal.

\section{Um parentesco não convertível}

A glória política dos líderes esconde uma realidade mais complexa das condições locais do exercício da autoridade. No final dos anos 1940, enquanto ainda se discutia as modalidades de aplicação da plena cidadania aos assuntos do Império, o pequeno grupo de intermediários melanésios que se formou em torno das escolas de missões estava preocupado tanto com os efeitos locais do exercício do direito de voto quanto com a desintegração do poder dos chefes. Por seu turno, o Serviço dos Assuntos Indígenas receava não encontrar parceiros para transmitir as decisões administrativas para o mundo "indígena". Deve-se dizer que a remoção do acantonamento em 1946 tornou possível se reconectar com uma grande quantidade de relações de parentesco que estavam fora das reservas suscetíveis de modificar os equilíbrios internos e então de mudar certas posições adquiridas. Por tudo isso, o poder dos chefes é primeiro implicado pelo seu papel durante o Indigenato e pela mutação das formas da legitimidade. No início da década de 1950, os representantes eleitos e os líderes impuseram a manutenção de certas disposições indígenas. As reservas mantinham seus status de territórios incompatíveis e inalienáveis. A distribuição de terras e as devoluções sucessoriais ainda não estavam sujeitas à lei do Estado, mas administradas "de acordo com o costume" no âmbito de um estatuto jurídico específico.

\section{Uma desintegração paradoxal}

A variedade dos status específicos do mundo "indígena" teve efeito sobre a integração na sociedade colonial. Particularmente, em relação aos chefes, as raras imagens dos arquivos disponíveis, as confidências e a experiência das entrevistas mostram trajetórias muito diferentes, como testemunhou, especialmente, a diversidade de posturas corporais. Alguns grandes chefes destacam-se do resto da população melanésia por um grande domínio de si mesmos e pelo uso de um francês com acento caledônio dificilmente perceptível ${ }^{22}$. Nas ilhas, a cor da pele também revela uma estratégia de clareamento da aparência física por alianças com famílias europeias. Em contrapartida, outros líderes possuem um controle

22 SORIANO, Éric. O fim dos "Indígenas" da Nova Caledônia: o colonial a prova do político (1946-1976). Paris: Karthala, 2014. 
fraco do discurso público devido aos olhares embebidos pelo álcool. Eles intervêm muito menos nas assembleias representativas, e muitos deles não deixam um traço de participação nos debates.

Depois de 1946, houveram vários discursos, desde dos administradores coloniais até das associações missionárias, que lamentaram o enfraquecimento do poder desses líderes na Grande Terre. De fato, ao permitir aos "indígenas" recuperar certas liberdades, a abolição do Código do Indigenato eliminou a maior parte de suas prerrogativas. Eles não precisaram mais aumentar o imposto de capitação, requisitar a força de trabalho ou denunciar os baderneiros. O procedimento oficial queria que a nomeação de um chefe fosse feita em duas etapas: primeiro, os representantes das "tribos" em questão formulavam uma proposição; então o Estado registrava (ou não) esta. Poderia acontecer que a sucessão de um líder provocasse um conflito.

Quando nenhum acordo parecia ser possível, o Estado utilizava, como último recurso, o critério de ascendência genealógica e nomeava o descendente mais direto de um líder falecido ou não mais em condições de conduzir os assuntos distritais. Ao fazê-lo, a administração sugeria que a "tradição" falava por si mesma quando se tratava das condições de legitimidade. Se é verdade que essa recondução hereditária se fazia naturalmente nas ilhas onde este critério parece ter funcionado regularmente antes da colonização, seu uso pelos agentes coloniais contribuiu para perturbar a lógica do reconhecimento do poder na Grande Terre. Ao criar discrepâncias significativas entre a realidade do exercício da autoridade local e sua consagração administrativa, o Estado deixava se perpetuar as pequenas vantagens que mantinham ativos os líderes com influência limitada. $O$ governo fazia assim uma distinção muito presente nas reservas entre chefes tradicionais e chefes administrativos.

Além disso, os debates lançados nas comunidades locais sobre a possível reestruturação da sociedade melanésia por meios legais revelam tanto uma diversidade de contextos locais quanto uma disparidade de relacionamentos com as regras de transmissão do poder nas reservas. Essa disparidade de pontos de vista se manifestou em 1958 durante uma discussão sobre a conveniência de melhorar os procedimentos coletivos de decisão e resolução de conflitos. O projeto era para inventar uma instituição - o Conselho dos Anciãos - a qual seria atribuída novas competências para atenuar a falta de legitimidade dos líderes. Se as posições se referiam a obrigações partidárias, cada um dos eleitos desempenhava a sua própria trajetória e as formas de seu status local, mais ou menos herdado e mais ou menos reconhecido pela administração. Os representantes eleitos sem status tradicional oficial tendiam a relativizar a posição de líder, enquanto os detentores desse status exibiam uma apreensão normativa do poder. Aqueles que descreviam os modos coletivos de regulamentação política entre os clãs se opunham àqueles que apresentavam o líder como a expressão do poder no mundo "indígena".

Um dos principais defensores da instituição, Émile Nechero, é um representante eleito da Grande Terra. Em seu distrito natal, as dinâmicas do poder anteriores a tomada de possessão foi amplamente 
recomposta pelas estratégias da administração colonial e pelo deslocamento das populações ${ }^{23}$. Ali o Estado Colonial reconheceu dois chefes em um território escassamente povoado e encravado entre montanhas e pântanos. Émile Nechero nasceu em 1914 na tribo Kuiné, em um clã de mestres do solo ancião ou caçula (isto é, com o status de guardião "apère tèpe" garantindo a distribuição dos espaços agrários). Foi seu clã que "cedeu" a aldeia aos colonos e talvez por isso ele ganhou um prestígio especial com a administração.

A partir de 1952, ele se juntou à UC onde teve uma longa carreira como membro eleito territorial e municipal. No entanto, este distrito está enfrentando fortes tensões e os saldos das propriedades foram estabelecidos apenas ao preço dos procedimentos coletivos externos para os chefes. Pode-se entender seu apego ao Conselho dos Anciãos, em um contexto tão complexo onde a contestação dos dois chefes é recorrente. Para ele, esta instituição é "muito antiga, ela sempre existiu"24. O sentido do debate é evidente quando as competências do Conselho dos Anciãos em matéria fundiária são questionadas pelos dois grandes chefes das Ilhas Lealdade. Henri Naisseline, eleito da oposição, diz que "automaticamente as terras pertencem ao chefe"25. Se as posições dos outros grandes líderes se revelam mais variadas, a dificuldade dos dirigentes em fornecer respostas definitivas demonstra uma pluralidade de situações locais e, especialmente, a capacidade diferenciada de uns e de outros para expressar as práticas usuais em um registro normativo. Nesse caso, a administração mantém uma posição padrão, voltando-se a uma visão específica da organização coletiva dos distritos que considera que as decisões de desconcentração e distribuição de terra será "de acordo com os costumes".

De fato, a sobre representação dos líderes é mais o produto de uma instrumentalização simbólica do que de uma legitimidade "tradicional" convertida em política. Esses títulos não garantem o benefício de uma esfera de influência, mas os líderes são, pelo menos, o sujeito de um investimento político, já que foram para o plano administrativo. A prática de recrutar grandes chefes é, portanto, frequente do lado das organizações associadas as antigas elites coloniais: perto de dois terços deles investem nestas organizações. Dos 17 grandes chefes eleitos para a Assembleia Territorial, 10 representam o campo "antiautonomista" cuja audiência no mundo "indígena" continua limitada. Esse uso é frequente na Grande Terre onde a influência política de grandes líderes como Nea Galet ou Kowi Bouillant é confirmada em vários mandatos. Em contraste, o forte controle social organizado em torno dos grandes líderes nas ilhas tem menos frequentemente resultado em uma conversão política desse tipo de posição e há muitas falhas.

\footnotetext{
${ }^{23}$ GUIART, J. "Dualismo e estrutura do controle social no país Canaca, Nova Caledônia". In: Homem, 2 (2), 1962, p. 49-79. DEMMER, C. "Segredos e organização política em Canaca: para deixar as categorias privadas/públicas"., art. citado, p. 79-104.

${ }^{24}$ Declaração de Émile Nechero, sessão extraordinária de fevereiro-março de 1958, 18ạ reunião, quinta-feira, 20 de março de 1958.

${ }^{25}$ Declaração de Henri Naisseline, ibid.
} 


\section{Duas configurações de herança política}

É ao descrever duas das principais situações da dinastia política que podemos aproveitar, por um jogo de espelho invertido, o possível uso do parentesco na política. No entanto, é mais uma questão de descrever as condições de possibilidade desta transmissão do que detalhar os mecanismos concretos. Essas condições são os produtos de duas configurações históricas favoráveis à ativação de estratégias que podem para dar um sentido político as relações até agora pensadas em termos de parentesco. Na verdade, os únicos eleitos do período a terem transmitido um capital político ao seu descendente direto são dois grandes líderes: Rock Pidjot da "tribo" da Concepção no sul da Grande Terre e Henri Naisseline chefe de Ghama na ilha de Maré. Estes dois exemplos de transmissão estão, além disso, colocando à prova uma incipiente independência nascida na década de 1970. Apesar de terem feito campanha pela manutenção da Nova Caledônia no quadro francês, esses dois membros eleitos legaram seus mandatos para dois dos personagens mais importantes do nacionalismo canaco. A descendência de Rock Pidjot se impôs como uma das famílias que ocupam posições estratégicas dentro das comunidades locais e da principal formação independentista. A filiação de Henri Naisseline é mais modesta, mas seu filho, Nidoish Naisseline, estendeu a ação do pai até tornar-se uma personalidade essencial no espaço político local.

Rock Pidjot nasceu na "tribo" da Concepção em 1907. Seu pai, Joseph Pidjot, casou-se com uma mulher branca da família Gauthier, o que raramente acontecia naquela época ${ }^{26}$. Rock Pidjot fez seus estudos na Escola Católica de Concepção e na de Santa Maria em Païta. Embora nenhum diploma sancione seu treinamento inicial, a passagem por essas escolas na década de 1920 constitui uma distinção essencial para sua promoção. Seu casamento com uma mulher da família Togna, cujo clã original é considerado o proprietário "tradicional" dos lugares, reforça sua inserção local. Esses recursos desempenham incontestavelmente um papel central em seu acesso a esse grande status principal do distrito, mesmo que eles não pareçam determinantes em termos estritamente eleitorais: a "tribo" da Concepção reúne um número reduzido de eleitores em um território permanentemente preso as vozes europeias, esmagadoramente anti-independência. É bastante forte seu investimento nos círculos católicos que predispuseram Rock Pidjot à vida política: a partir de 1953, ele é sistematicamente apoiado pela UC. Sua longa amizade com o principal líder europeu dessa formação e com outras fontes lhe permitiram fazer a carreira política mais estável do período pós-guerra. Ele participou diretamente da criação da UC da qual foi nomeado presidente fundador, então se tornou ministro da Economia rural entre 1957 e 1960 durante o período da lei-quadro. A partir de 1964, após ter assumido uma série de mandatos territoriais, tornou-se

26 TREPIED, B. "Roch Pidjot, um grande canaco na política". In: Revue juridique, politique et économique de la Nouvelle-Calédonie, 16,2010 , p. 56-65. 
deputado, após a condenação de Maurice Lenormand ${ }^{27}$, e sempre foi reeleito até sua morte em 1990. Sua singularidade é ter acompanhado o momento independentista de 1977, ao contrário da maioria dos eleitos de sua geração, e ter sido a origem de uma verdadeira filiação de líderes políticos, associativos e administrativos com ligações de parentesco até os dias atuais.

É durante as últimas décadas de sua carreira que ele acompanha a carreira de seus netos que foram estudar na metrópole. Um deles, Rock Wamytan, começa uma carreira intimamente associada à experiência adquirida com seu avô ${ }^{28}$. O caminho político que o leva a assumir a direção da UC mostra o quanto as estruturas da seleção finalmente evoluíram: a distinção acadêmica e a influência partidária superam sua implantação local. Do lado de seu pai, que foi motorista da antiga mina local, ele é o neto do chefe da "tribo" de São Luís e, do lado de sua mãe, é neto de Rock Pidjot. Roch Wamytan, graduado em Economia pela Universidade de Lyon, tornou-se o assistente parlamentar de seu avô, assumiu as responsabilidades administrativas dentro do Escritório Cultural, Científico e Técnico de Canaca (OCSTK) a partir de 1978. Em outras palavras, ele acumulou recursos sociais e políticos que o colocaram em uma posição de destaque no final dos anos 1980, após a morte de vários líderes dirigentes nacionalistas. No entanto, se seguimos sua ascensão política, vemos que isso se deve pouco ao seu investimento partidário. No Congresso de Lifou em 1981, ele foi nomeado para ocupar a presidência da "Comissão da Economia"29, mas renunciou rapidamente. Então ele desapareceu dos organogramas e não apareceu mais no Escritório Político e nem mesmo na comissão executiva do Movimento até 1987. O encontraremos nessa comissão em 1988, e três anos depois chegou a presidência da FLNKS (Front de libération nationale kanak et socialiste). Embora até esse momento ele não tenha participado de nenhuma das instâncias diretivas da UC, foi promovido ao cargo de chefe do comitê de acompanhamento dos acordos de Matignon em 1989. Roch Wamytan encarna perfeitamente a figura do líder identificada com uma organização política apenas pertencendo a uma "tribo" da UC e ocupando rapidamente um lugar central no seio da organização sem subir a escada interna. Sua filiação com Rock Pidjot e seus diplomas universitários constituem aqui recursos de primeira ordem.

A trajetória de Henri Naisseline é politicamente mais frágil, mas socialmente mais proeminente. Sua carreira é emblemática de uma posição habitual herdada, que ele converteu ao plano eleitoral, mas que ele apenas pode fazer frutificar a favor de uma estratégia de distinção política. Isso lhe permitiu ao mesmo tempo afirmar a autonomia de sua liderança e jogar com os laços privilegiados que possuía com as elites

\footnotetext{
27 Nota da tradutora: Maurice Joseph Henri Lenormand (1913-2006), francês, foi deputado da Nova Caledônia de 1951 a 1964 e uma das principais figuras políticas deste território entre as décadas de 1950-1970. Foi condenado em 1964 a um período de inelegibilidade devido a sua participação em uma briga em Nouméa, perdendo a sua cadeira de deputado da Assembleia Territorial. Rock Pidjot então o sucedeu como deputado.
}

${ }^{28}$ Entrevista com Rock Wamytan, Noumea, 7 de junho de 1994.

${ }^{29}$ Relatório do Congresso da UC, Couli, de 11 a 14 de novembro de 1982. 
caledônias no momento das nomeações. Ele nasceu na "tribo" de Netché e é o filho mais velho do grande chefe Henri Naisseline e da filha de um comerciante de origem inglesa estabelecido em Maré. Muito jovem no momento da morte de seu pai, ele se tornou grande chefe somente em 1936, depois de um período de regência assumido por um de seus tio-avó. Sua posição permitiu que ele fosse um dos primeiros melanésios a frequentar o Liceu Lapérouse em Nouméa, ao lado dos filhos da burguesia noumeaense. Ele fez seu serviço militar na Marinha Nacional e expressou seu apoio ao General de Gaulle desde 1940, indo até mesmo hastear a bandeira francesa no meio de sua "tribo" e enviando para o combate um grande número de "voluntários" sob sua liderança. Sua entrada na política não é apenas marcada por esse compromisso, é especialmente guiada por uma estratégia de distanciamento das associações missionárias (e da UC). Em 1946, ele se filiou ao Partido Comunista Caledônio que desapareceu alguns meses depois. Ele se engajou nos movimentos que divulgavam o gaullismo, se integrou na seção local da União para a Nova República (UNR) sendo eleito para a Assembleia Territorial da Nova Caledônia de 1957 a 1967. O partido gaullista o nomeou como suplente durante as eleições senatoriais, e depois as legislativas de 1959. Sua carreira política terminou quando produziu uma divisão no UNR local em 1966.

A partir da década de 1970, seu filho, Nidoish Naisseline, que fez mestrado em Sociologia na metrópole no final da década de 1960, ganha destaque seguindo um caminho político diferente ${ }^{30}$ : sua estratégia consistiu em manter-se distante das grandes organizações políticas para garantir a autonomia do seu status local. Trata-se ao mesmo tempo de dar vida à singularidade de sua liderança na ilha de Maré e de manter a fidelidade eleitoral e matrimonial dos grupos de parentesco localizados no extremo norte e na costa leste da Grande Terre, os quais mais tarde apoiaram eleitoralmente sua campanha em oposição à UC. Sua conversão para o nacionalismo canaco só parcialmente o colocou em desacordo com a herança de seu pai. Nidoish Naisseline seguiu um caminho autônomo dentro do movimento independentista, sempre à distância das formações majoritárias. Iniciador do Partido da Liberação Canaca (Kanak Liberation Party Palika) em 1975, ele se dissociou para liderar em 1981 a Liberação Socialista Canaca (Liberation Socialist Kanak - LKS), do qual ele será o único eleito para assumir vários mandatos. Sem o apoio dos principais partidos políticos, sua busca pela singularidade o impediu de prolongar sua carreira eletiva além da década de 1990. No entanto, ele se tornou presidente do conselho de administração da companhia aérea que fornecia rotas domésticas para Nova Caledônia (Aircal) em 2004 e continuará a ser presidente da Comissão da Organização dos Transportes e da Comunicação do Congresso até 2009.

Essas duas lógicas de herança estão associadas a configurações históricas singulares. Elas vêm de oportunidades conjuntas para ganhar uma posição e uma liderança reconhecidas pelo Estado e para se beneficiar de uma distinção social excepcional no mundo "indígena". É esse o controle que permite a Roch

30 CHAPPELL, David. "O despertar de Canaca de 1969-1976: radicalismo anticolonial na Nova Caledônia". In: Journal of the Society of Oceanists, 117 (2), 2003, p. 187-202. 
Pidjot e a Henri Naisseline de retraduzirem em termos de parentesco uma ascensão tanto social quanto política.

A liderança de Roch Pidjot é o produto das recomposições operadas na Grande Terre durante o período colonial e que possibilitou uma proximidade com os mundos europeus, apesar de Roch Pidjot não ter vindo de uma aristocracia tradicional. O seu grupo de parentesco entra em contato com os missionários da Sociedade de Maria, em 1843, na área de Balade, nordeste da Grande Terre. Uma parte desse grupo é então deslocado do norte para o sul da ilha como parte de um projeto para fundar uma vila indígena cristã perto de Port-de-France (rebatizada Noumea em 1866). É neste contexto que são criadas Concepção, depois São Luís onde outros "clãs" vindos da área de Touho também são reagrupados ${ }^{31}$. Essas duas "reduções" hoje são consideradas pela administração como "tribos" e distritos.

Por sua vez, a família Naisseline deve seu status local a uma história que remonta ao século XIX, durante o qual foi criada uma nova divisão, cuja administração o fez um distrito ${ }^{32}$. Em 1898, a liderança de Guahma acolheu em Maré a Sociedade das Missões Evangélicas de Paris para substituir a Sociedade Missionária Britânica. No mesmo ano, a administração francesa declarou a ilha "reserva integral" e a dividiu em distritos consuetudinários. A liderança de Guahma é o produto de conflitos provavelmente relacionados com a chegada das populações migrantes provindas das ilhas polinésias e cujas memórias orais e míticas deram origem, até hoje, a várias interpretações que remontam ao final do século XVIII. O nascimento de Guahma e sua institucionalização em torno de Naisseline datam do início do século XIX, e essa liderança deve sua estabilidade a suas relações de parentesco aos chefes dos clãs de Lifou ${ }^{33}$. É também neste momento que parece remontar sua estratégia de hereditariedade do poder. A partir daí, tanto para os Naisseline quanto para os Pidjot, o que parece determinante é o reconhecimento de sua liderança pela administração e sua constituição em distritos e "tribos".

Na Nova Caledônia, os fenômenos de hereditariedade política revelam mais estratégias coloniais do que confirmam as lógicas de transmissão de poder herdado de um passado distante. No entanto, embora o Estado colonial tenha, por conveniência, jogado o jogo da transmissão filial, a lógica da votação e as formas segmentárias da organização do poder mostraram-se muitas vezes tentativas ineficazes de transmissão hereditária dos recursos políticos. Quando ela existe, esta transmissão é o produto de outros fatores, tais como o controle de um aparelho partidário e das lógicas da reprodução social. São esses os elementos que permitem o uso político e simbólico de uma posição local e a possível tradução de uma ascensão política

\footnotetext{
${ }^{31}$ DAUPHINE, Joel. Pouebo: história de uma tribo canaca sob o Segundo Império. Paris: L'Harmattan, 1992.

32 HOWE, Kerry Ross. Ilhas Lealdade: uma história da cultura do contato (1840-1900). Canberra: Australina National University Press, 1977

33 WORSLEY, Peter. The Trumpet Shall Sound: um estudo dos cultos de "cargo" na Melanésia. Londres: McGibbon \& Ker, 1957. DUBOIS, Marie-Joseph. Pessoas de Maré. Paris: Edição de Anthropos, 1984.

GUIART, J. Estrutura da liderança na Melanésia do Sul. op. cit.
} 
em termos de hereditariedade "tradicional". Pelo menos podemos notar a incapacidade dos partidos políticos na Oceania de superar as restrições de parentesco na seleção dos líderes ${ }^{34}$. 0 exame minucioso das trajetórias dos eleitos da Nova Caledônia também mostra o quanto as restrições partidárias, por mais tênues que sejam, acompanham a mutação definitiva do status do parentesco. A difusão progressiva de outras formas de legitimidade (escolar, salarial, religiosa) tornou este status um capital específico do qual a eficácia política depende do acesso a outros recursos.

${ }^{34}$ ANCKAR, Dag Anckar e ANCKAR, Carsten. «Democracias sem partidos». In : Comparative Political Studies, 33, 2000, p. $225-247$. RATUVA, Steven. «Política primordial? Partidos políticos e tradição na Melanésia». In : RICH, Roland; HAMBLY, Luke e MORGAN, Michael G.(orgs). Partidos políticos nas Ilhas do Pacífico. Canberra: Australian National University, 2008, p. 27-4. 